\title{
Evaluation of Hepatotoxicity with Treatment Doses of Flucytosine and Amphotericin B for Invasive Fungal Infections
}

\author{
Alexandra Folk, ${ }^{1}$ Coralia Cotoraci, ${ }^{2}$ Cornel Balta, ${ }^{3}$ Maria Suciu, ${ }^{3}$ \\ Hildegard Herman, ${ }^{3}$ Oana Maria Boldura, ${ }^{4}$ Sorina Dinescu, ${ }^{5}$ Lucian Paiusan, ${ }^{1}$ \\ Aurel Ardelean, ${ }^{3}$ and Anca Hermenean ${ }^{3,6}$ \\ ${ }^{1}$ Department of Pathology, Faculty of Medicine, "Vasile Goldis" Western University of Arad, 86 Rebreanu Street, 310414 Arad, Romania \\ ${ }^{2}$ Department of Bioethics, Faculty of Medicine, "Vasile Goldis” Western University of Arad, 86 Rebreanu Street, 310414 Arad, Romania \\ ${ }^{3}$ Institute of Life Sciences, Vasile Goldis Western University of Arad, 86 Rebreanu, 310414 Arad, Romania \\ ${ }^{4}$ Faculty of Veterinary Medicine, Department of Chemistry, Biochemistry and Molecular Biology, \\ Banat University of Agricultural Sciences and Veterinary Medicine "King Mihai I of Romania" Timisoara, 119 Calea Aradului, \\ 300645 Timisoara, Romania \\ ${ }^{5}$ Department of Biochemistry and Molecular Biology, University of Bucharest, 91-95 Splaiul Independentei, 050095 Bucharest, Romania \\ ${ }^{6}$ Department of Histology, Faculty of Medicine, "Vasile Goldis" Western University of Arad, 86 Rebreanu Street, 310414 Arad, Romania
}

Correspondence should be addressed to Anca Hermenean; anca.hermenean@gmail.com

Received 16 September 2015; Revised 6 December 2015; Accepted 9 December 2015

Academic Editor: Bo Zuo

Copyright (C) 2016 Alexandra Folk et al. This is an open access article distributed under the Creative Commons Attribution License, which permits unrestricted use, distribution, and reproduction in any medium, provided the original work is properly cited.

\begin{abstract}
Invasive fungal infection is a well-known cause of morbidity and mortality in immunocompromised patients. In this study we aimed to evaluate the hepatotoxicity induced by combined therapy of flucytosine and amphotericin $\mathrm{B}$, at three different doses administered to mice for 14 days: $50 \mathrm{mg} / \mathrm{kg}$ flucytosine and $300 \mu \mathrm{g} / \mathrm{kg}$ amphotericin B; $100 \mathrm{mg} / \mathrm{kg}$ flucytosine and $600 \mu \mathrm{g} / \mathrm{kg}$ amphotericin B; $150 \mathrm{mg} / \mathrm{kg}$ flucytosine and $900 \mu \mathrm{g} / \mathrm{kg}$ amphotericin B. Liver injuries were evaluated by analysis of optic and electron microscopy samples, changes in TNF- $\alpha$, IL-6, and NF- $\kappa$ B inflammation markers levels of expression, and evaluation of mRNA profiles. Histological and ultrastructural analysis revealed an increase in parenchymal and portal inflammation in mice and Kupffer cells activation. Combined antifungal treatment stimulated activation of an inflammatory pathway, demonstrated by a significant dose-dependent increase of TNF- $\alpha$ and IL- 6 immunoreactivity, together with mRNA upregulation. Also, NF- $\kappa$ B was activated, as suggested by the high levels found in hepatic tissue and upregulation of target genes. Our results suggest that antifungal combined therapy exerts a synergistic inflammatory activation in a dose-dependent manner, through NF- $\kappa$ B pathway, which promotes an inflammatory cascade during inflammation. The use of combined antifungal therapy needs to be dose limiting due to the associated risk of liver injury, especially for those patients with hepatic dysfunction.
\end{abstract}

\section{Introduction}

Invasive fungal infection is a well-known cause of morbidity and mortality in immunocompromised patients, including those with transplantation, hematological malignancies, or corticosteroid therapy.

Three classes of antifungal agents are extensively used for treatment of systemic fungal infections: polyenes, azoles, and echinocandins. The polyene class of antifungal drugs is divided into conventional polyenes (nystatin, amphotericin
B-deoxycholate) and lipid-based formulations of amphotericin B. Polyenes are recommended in cases of intolerance to azoles or echinocandins, when the organism becomes resistant to other agents, or in the case of uncertainty infection due to non-Candida yeast [1].

Amphotericin $\mathrm{B}$ was the first antifungal drug available to treat systemic fungal infections, commonly used in cases of most yeasts and filamentous fungi, disseminated candidiasis, and invasive pulmonary aspergillosis [2]. Its primary mechanism of action acts via binding to ergosterol, located in the 

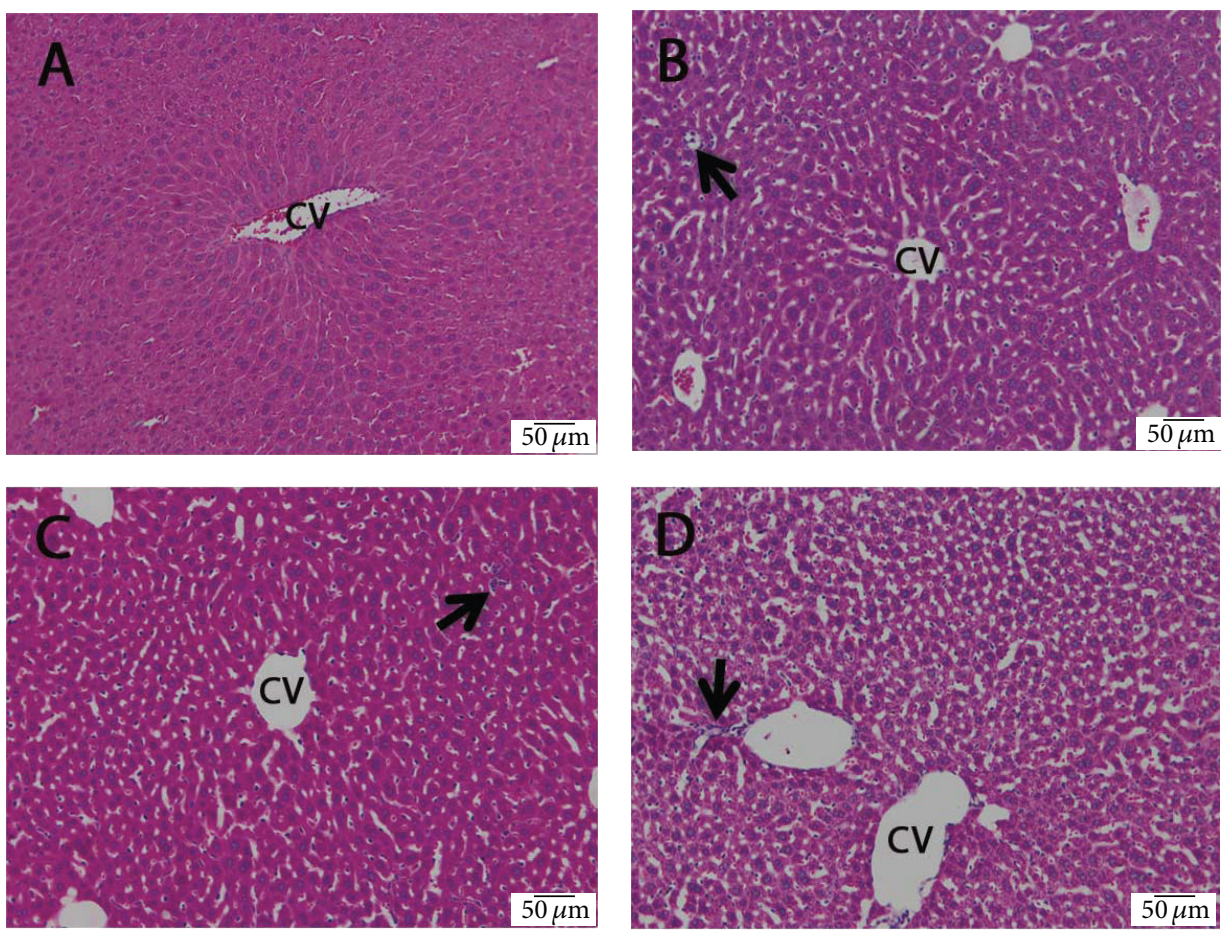

FIGURE 1: The effect of flucytosine and amphotericin B coadministration on histological changes in the livers of experimental mice: (A) control group; (B) $50 \mathrm{mg} / \mathrm{kg}$ flucytosine $+300 \mu \mathrm{g} / \mathrm{kg}$ amphotericin B group; (C) $100 \mathrm{mg} / \mathrm{kg}$ flucytosine $+600 \mu \mathrm{g} / \mathrm{kg}$ amphotericin B group; (D) $150 \mathrm{mg} / \mathrm{kg}$ flucytosine $+900 \mu \mathrm{g} / \mathrm{kg}$ amphotericin B group. CV: centrilobular vein; arrow: inflammatory cell infiltration.

cell membrane of sensitive fungi, followed by increase of cell membrane permeability and possibly leading to cell death [3]. Meanwhile, the efficacy of amphotericin B is filled up by the drug's ability to stimulate macrophages [4].

Flucytosine is a synthetic antimycotic compound without intrinsic antifungal capacity. After intake, it is converted to 5-fluorouracil and then to metabolites that inhibit fungal RNA and DNA synthesis [5]. Flucytosine monotherapy is used only in chromoblastomycosis and vaginal and lower urinary tract candidosis [5]. In all other situations, flucytosine is used together with other agents, for systemic fungal infections caused by sensitive organisms, because of the rapid emergence of resistance when used alone. The combination of flucytosine with amphotericin B has been shown to be beneficial in clinical study with cryptococcal meningitis [6] and its use is recommended [7]. Penetration of the drug into the eye and central nervous system is good [8].

The incidence rates of treatment discontinuation due to adverse reactions associated with antifungal therapy were higher than $10 \%$ for amphotericin $\mathrm{B}$ and itraconazole and $2.5 \%$ to $3.8 \%$ for fluconazole, caspofungin, and micafungin, whereas $1.5 \%$ of the patients stopped itraconazole treatment due to hepatotoxicity [9]. Furthermore, hepatotoxicity without treatment discontinuation was recorded for voriconazole and flucytosine monotherapy that ranges between 0 and $25 \%$ $[5,10]$.

Based on the well-established side-effect profiles for both monotherapies of flucytosine and amphotericin B, we aimed to evaluate the hepatotoxicity induced by combined therapy, at increasing doses. In the present study, we hypothesized that toxicity of flucytosine and amphotericin B coadministration is dose limiting via cytokine-mediated proinflammatory activity.

\section{Material and Methods}

2.1. Materials. Amphotericin B was purchased from BristolMyers Squibb (Saint-Remy-sur-Avre, France) and flucytosine (Ancotil, MEDA Pharma, Paris, France). Anti-TNF- $\alpha$, IL6 , and NF- $\kappa \mathrm{B}$, antibodies were supplied from Santa Cruz Biotechnology (Santa Cruz, CA, USA) and Novocastra kit for immunohistochemistry was purchased from Leica Microsystems (Germany).

\subsection{Animals and Experimental Procedure. Adult male CD1} mice weighing $25 \pm 3 \mathrm{~g}$ were obtained from Animal Facility of "Vasile Goldis" Western University of Arad, Romania. All experimental procedures were approved by the Ethical Committee of "Vasile Goldis" Western University of Arad.

The mice were divided into four groups:

Group 1: control mice received by gavage the equivalent volume of $0.9 \%$ normal saline solution for 14 days.

Group 2: mice received $50 \mathrm{mg} / \mathrm{kg}$ flucytosine by gavage and were intraperitoneally injected with $300 \mu \mathrm{g} / \mathrm{kg}$ amphotericin B for 14 days.

Group 3: mice received $100 \mathrm{mg} / \mathrm{kg}$ flucytosine by gavage and were intraperitoneally injected with $600 \mu \mathrm{g} /$ $\mathrm{kg}$ amphotericin B for 14 days. 

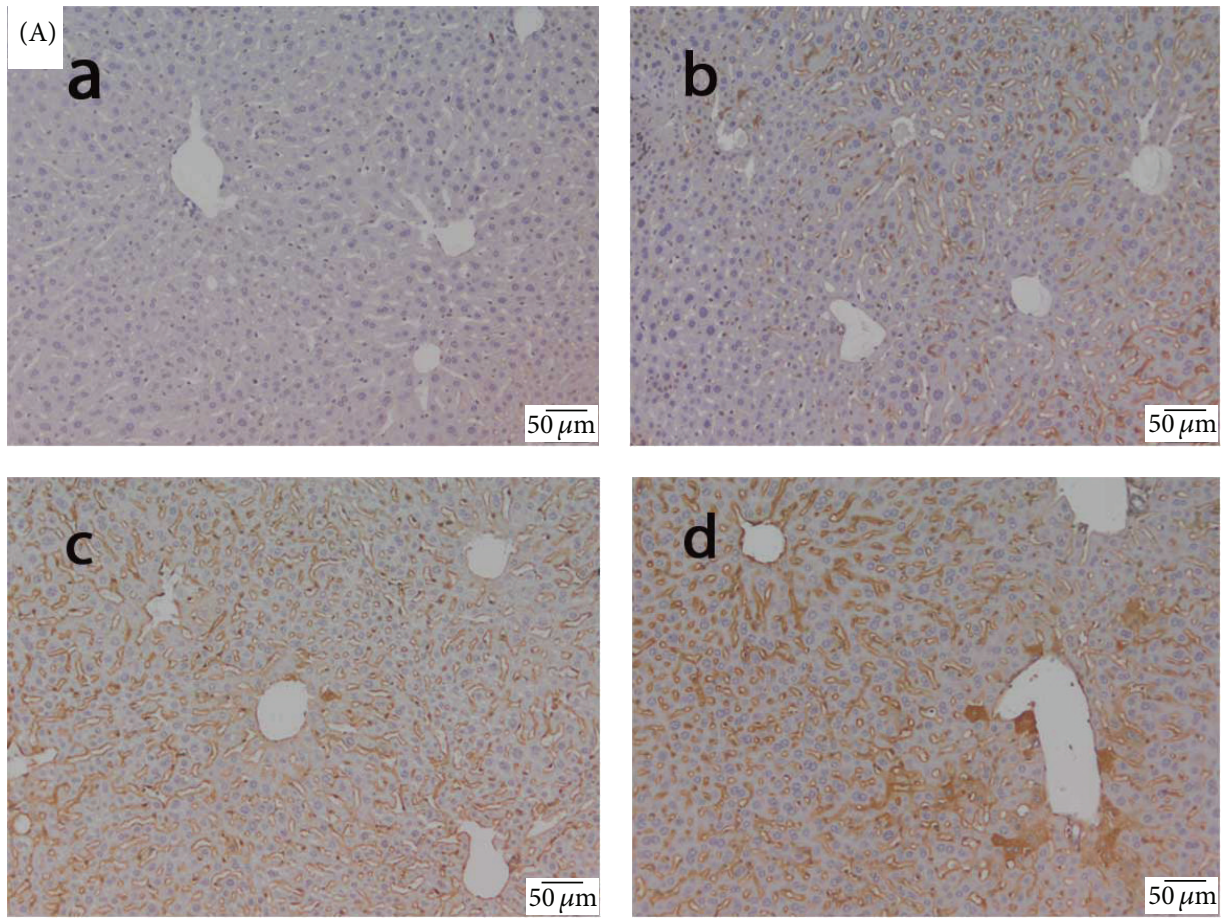

(B)

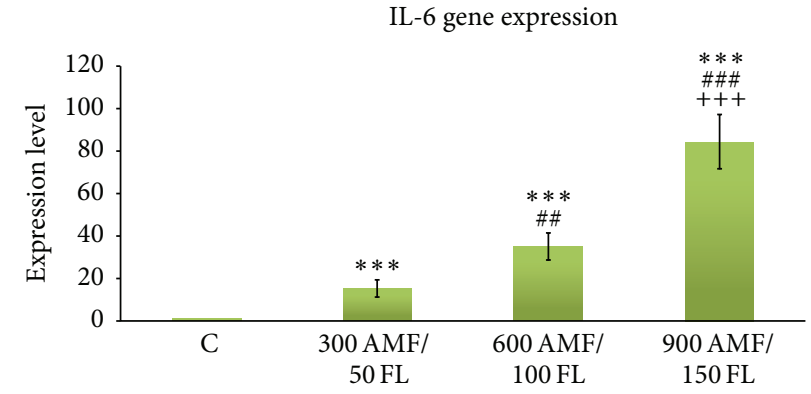

FIGURE 2: The effect of flucytosine and amphotericin B coadministration on the gene expression and specific hepatic distribution of IL-6. (A): (a) control group; (b) $50 \mathrm{mg} / \mathrm{kg}$ flucytosine $+300 \mu \mathrm{g} / \mathrm{kg}$ amphotericin B group; (c) $100 \mathrm{mg} / \mathrm{kg}$ flucytosine $+600 \mu \mathrm{g} / \mathrm{kg}$ amphotericin B group; (d) $150 \mathrm{mg} / \mathrm{kg}$ flucytosine $+900 \mu \mathrm{g} / \mathrm{kg}$ amphotericin B group; (B) real-time PCR was used to investigate mRNA levels of IL-6 target genes. Significance levels are marked as follows: ${ }^{* * *} P<0.001$ compared with control, \#\# $<0.01$ and ${ }^{\# \# \#} P<0.001$ compared with $300 \mathrm{AMF} / 50 \mathrm{FL}$ group, and ${ }^{+++} P<0.001$ compared with $600 \mathrm{AMF} / 50$ FL group.

Group 4: mice received $150 \mathrm{mg} / \mathrm{kg}$ flucytosine by gavage and were intraperitoneally injected with $900 \mu \mathrm{g} /$ $\mathrm{kg}$ amphotericin B for 14 days.

The selection of three doses of combined flucytosineamphotericin B cotreatment was based on previous published reports, related to systemic antifungal efficacy $[5,11,12]$.

Mice were sacrificed 24 hours after the last administration and liver samples were used for histopathology, immunohistochemistry, and electron microscopy.

2.3. Histopathology. The liver was cut into small pieces and fixed in $4 \%$ paraformaldehyde. Following dehydration in an ascending series of ethanol, the tissue samples were cleared in toluene, embedded in paraffin, and sliced into $5 \mu \mathrm{m}$ sections. The sectioned samples were stained with haematoxylin and eosin (H\&E). Sections were examined using an Olympus
BX43 microscope and photographed using a digital camera (Olympus XC30).

2.4. Immunohistochemistry. Immunohistochemical studies were performed on paraffin embedded liver tissue sections of $5 \mu \mathrm{m}$ thickness, previously deparaffinized, and rehydrated by using a standard technique. Rabbit polyclonal anti-TNF$\alpha$, IL-6, and NF- $\kappa$ B p65 diluted 1:100 (Santa Cruz, CA, USA) were used as primary antibodies. Immunoreactions were visualized employing Novocastra (Leica Biosystems, Germany), Peroxidase/DAB kit, according to the manufacturer's instructions. Negative control sections were processed by substitution of primary antibodies with irrelevant immunoglobulins of matched isotype, used in the same conditions as primary antibodies. Stained slides were analyzed by light microscopy (Olympus BX43, Hamburg, Germany). 

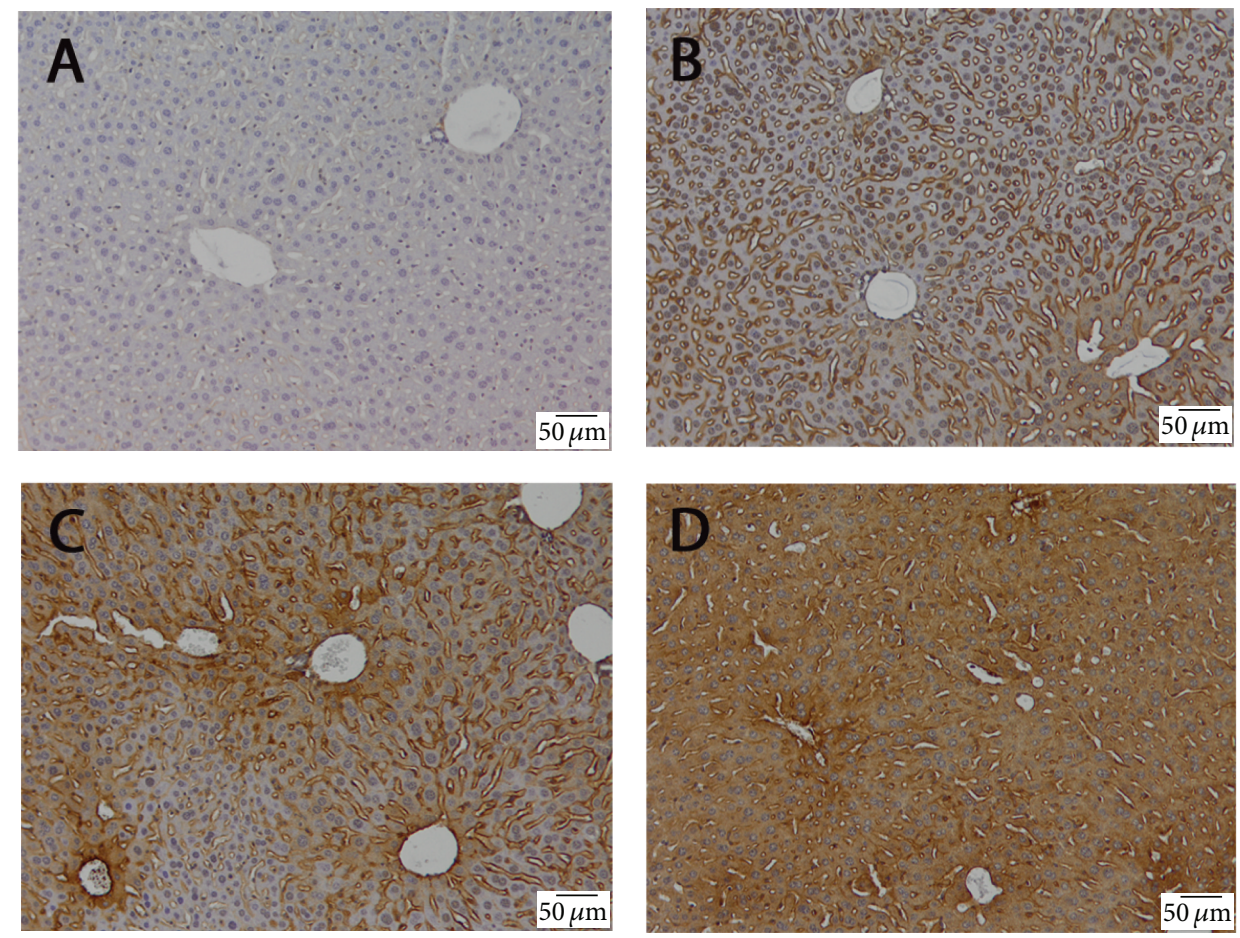

FIGURE 3: The effect of flucytosine and amphotericin B coadministration on the expression and specific hepatic distribution of TNF- $\alpha$ : (A) control group; (B) $50 \mathrm{mg} / \mathrm{kg}$ flucytosine $+300 \mu \mathrm{g} / \mathrm{kg}$ amphotericin B group; (C) $100 \mathrm{mg} / \mathrm{kg}$ flucytosine $+600 \mu \mathrm{g} / \mathrm{kg}$ amphotericin B group; (D) $150 \mathrm{mg} / \mathrm{kg}$ flucytosine $+900 \mu \mathrm{g} / \mathrm{kg}$ amphotericin B group.

2.5. RT-PCR Analysis. Total RNA from liver and kidney mouse tissues was isolated and purified using $S V$ Total RNA Isolation System (Promega), following the manufacturer's instructions. Quantity and quality of purified RNA were assessed using a NanoDrop 8000 spectrophotometer (Thermo Scientific). cDNA was synthesized from $2 \mu \mathrm{g}$ of total RNA using First Strand cDNA Synthesis Kit (Thermo Scientific) and oligo $\mathrm{d}(\mathrm{T})_{8}$ primer. $2 \mu \mathrm{L}$ of RT-PCR reaction results was used as template in qPCR experiments. Real-time PCR was performed using Luminaris HiGreen qPCR Master Mix, low ROX (Thermo Scientific) with Mx3000P real-time PCR system. Samples were run in triplicate. The primers sequences and all experimental validation data were obtained from the PrimerBank website: http://pga.mgh.harvard.edu/ primerbank/. Primers were synthesized by Eurogentec, Belgium (Table 1).

The ratio for the gene expression was normalized using GAPDH. Results were interpreted by $2^{\Delta \Delta C(T)}$ method [13].

2.6. Electron Microscopy. EM liver samples were prefixed with $2.7 \%$ glutaraldehyde solution in $0.1 \mathrm{M}$ phosphate buffer at $4^{\circ} \mathrm{C}$ for $1.5 \mathrm{~h}$, washed in $0.15 \mathrm{M}$ phosphate buffer $(\mathrm{pH}$ 7.2 ), and postfixed in $2 \%$ osmic acid solution in $0.15 \mathrm{M}$ phosphate buffer. Dehydration was performed in acetone and samples were embedded in the epoxy embedding resin Epon 812. Thick sections of $60 \mathrm{~nm}$ were cut with Leica EM UC7 ultramicrotome and analyzed with a TEM Tecnai 12 Biotwin electron microscope.
2.7. Statistical Analysis. Statistical analysis was conducted with a one-way ANOVA using Stata 13 software (StataCorp LP, Texas, USA). A value of $P<0.05$ was considered to be statistically significant.

\section{Results}

3.1. Flucytosine and Amphotericin B Coadministration Induced Histopathological Changes. Liver sections from control mice showed normal liver architecture (Figure $1(\mathrm{~A})$ ). In the flucytosine-amphotericin B groups, sinusoidal dilatation, inflammatory cell infiltration, and vascular congestion were present (Figure 1(B-D)). The structural changes were dosedependent.

3.2. Flucytosine and Amphotericin B Coadministration Upregulates Production of Hepatic Proinflammatory Cytokines. The effects of flucytosine and amphotericin B coadministration on the IL-6 expression are shown in Figure 2. The livers of control mice did not show substantial IL-6 immunopositivity (Figure $2 \mathrm{~A}(\mathrm{a})$ ). Flucytosine-amphotericin B cotreatment increased the number of cells labeled with IL-6 antibody in dose-dependent manner (Figure $2 \mathrm{~A}(\mathrm{~b}-\mathrm{d})$ ). The results obtained by immunohistochemistry were confirmed by the results of IL- 6 gene expression analysis, where IL- 6 levels significantly increased with $15.16 \%, 35.08 \%$, and $84.32 \%$ for antifungal cotreated groups as compared to the corresponding levels in the control group (Figure 2(B)). 

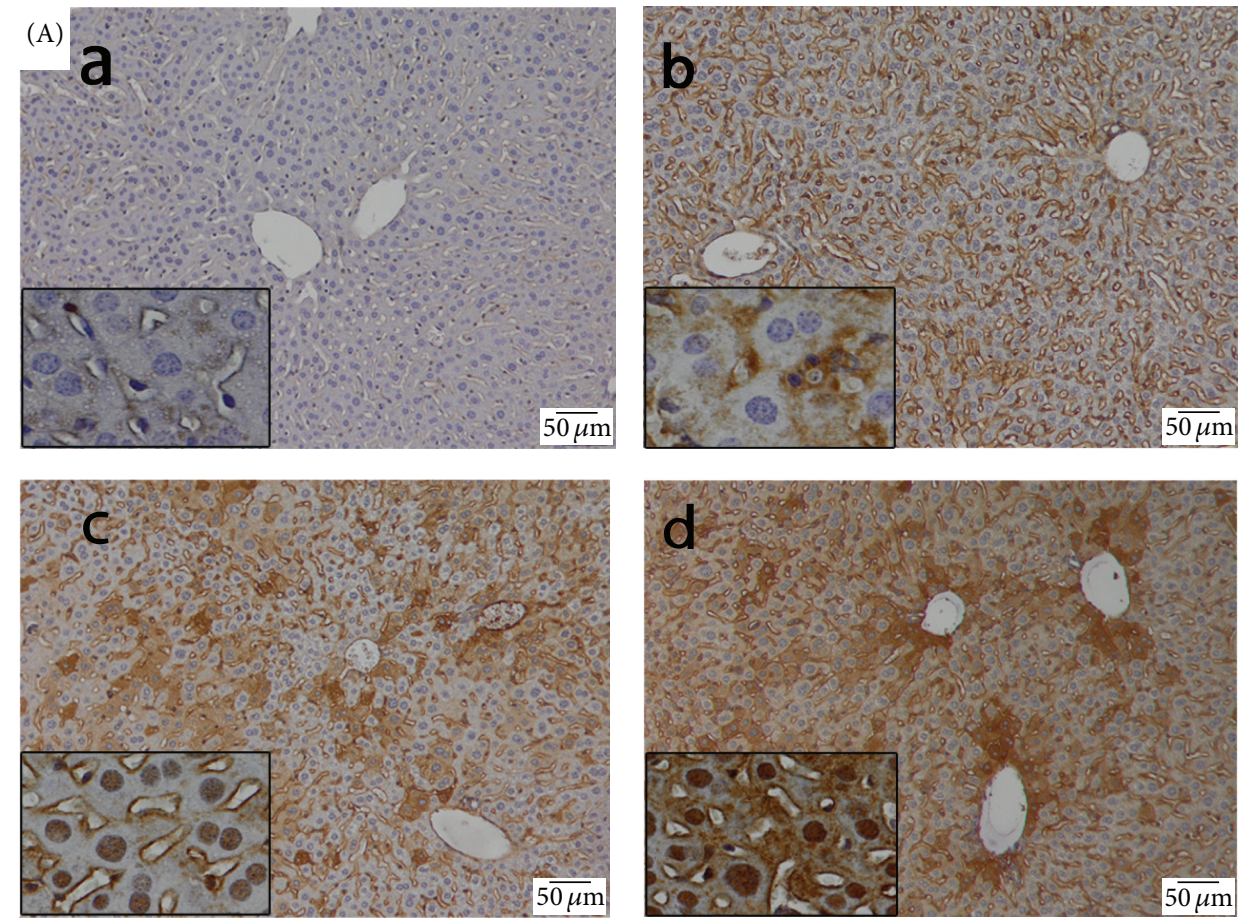

(B)

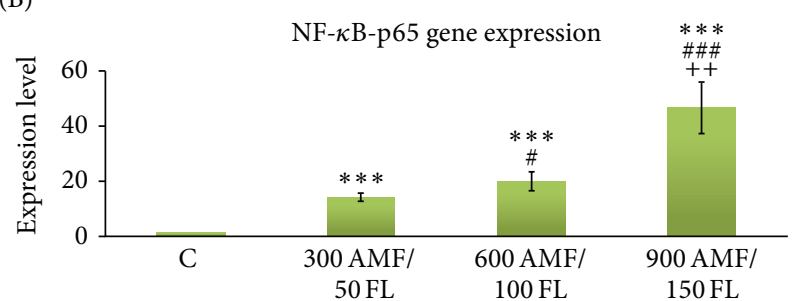

FIGURE 4: The effect of flucytosine and amphotericin B coadministration on the gene expression and specific hepatic distribution of NF- $\kappa \mathrm{B}$ p65 (A): (a) control group; (b) $50 \mathrm{mg} / \mathrm{kg}$ flucytosine $+300 \mu \mathrm{g} / \mathrm{kg}$ amphotericin B group; (c) $100 \mathrm{mg} / \mathrm{kg}$ flucytosine $+600 \mu \mathrm{g} / \mathrm{kg}$ amphotericin B group; (d) $150 \mathrm{mg} / \mathrm{kg}$ flucytosine $+900 \mu \mathrm{g} / \mathrm{kg}$ amphotericin B group; (B) real-time PCR was used to investigate mRNA levels of IL-6 target genes. Significance levels are marked as follows: ${ }^{* * *} P<0.001$ compared with control, \# $<0.05$ and ${ }^{\# \# \#} P<0.001$ compared with $300 \mathrm{AMF} / 50 \mathrm{FL}$ group, and ${ }^{++} P<0.01$ compared with $600 \mathrm{AMF} / 50 \mathrm{FL}$ group.

TABLE 1: Primer sequences used in the study.

\begin{tabular}{lll}
\hline Code & Sense & Antisense \\
\hline GAPDH & CGACTTCAACAGCAACTCCCACTCTTCC & TGGGTGGTCCAGGGTTTCTTACTCCTT \\
IL-6 & AAAGAGTTGTGCAATGGCAATTCT & AAGTGCATCATCGTTGTTCATACA \\
NF- $\kappa$ B p65 & CTTGGCAACAGCACAGACC & GAGAAGTCCATGTCCGCAAT \\
\hline
\end{tabular}

TNF- $\alpha$ expression was found in the treated groups (Figure 3). TNF- $\alpha$ immunoreactivity was observed mainly around centrilobular areas. No apparent TNF- $\alpha$ expression was detected in nonparenchymal cells. Treatment with antifungal drugs resulted in an increase of TNF- $\alpha$ expression in a dose-dependent manner, being the most prominent in mice treated with $150 \mathrm{mg} / \mathrm{kg}$ flucytosine $+900 \mu \mathrm{g} / \mathrm{kg}$ amphotericin B (Figure 3(D)).

3.3. Effect of Flucytosine and Amphotericin B Coadministration on the Activation of $N F-\kappa B$. The livers of control mice did not show substantial NF- $\kappa$ B immunopositivity (Figure 4
$A(a)$ ). Liver sections from mice coadministered with flucytosine and amphotericin B have shown strong immunopositivity, remarkably in the periportal and perilobular areas (Figure $4 \mathrm{~A}(\mathrm{~b}-\mathrm{d})$ ). The results were similar for mRNA levels of NF- $\kappa$ B: they were significantly increased for $50 / 300$, $100 / 600$, and 150/600 of flucytosine-amphotericin B coadministered groups 13.88-, 19.85-, and 46.61-fold, respectively, compared to control group (Figure 4(B)).

3.4. Flucytosine and Amphotericin B Coadministration on the Activation of Kupffer Cells. Mouse Kupffer cells are commonly identified using the F4/80 marker [14]. 

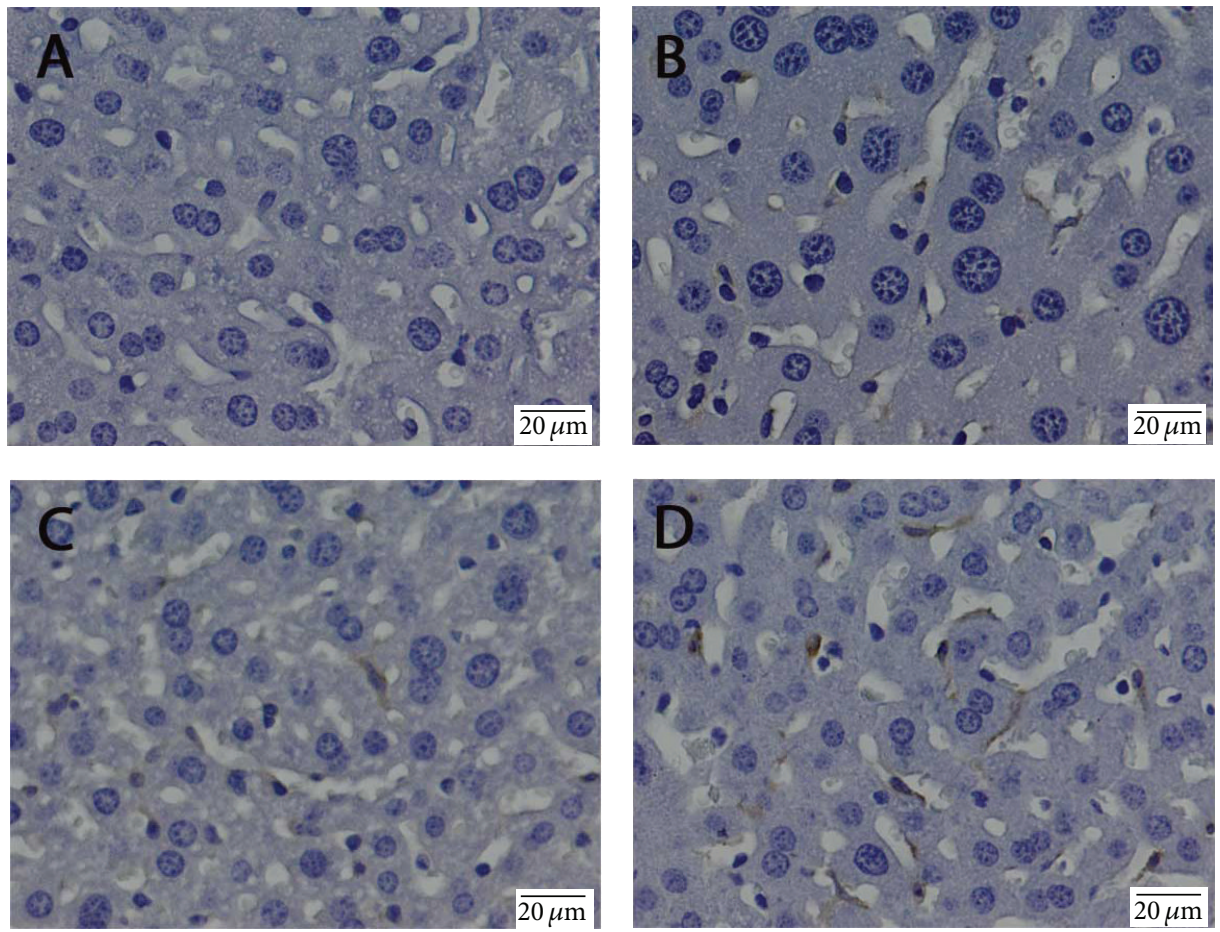

FIGURE 5: The effect of flucytosine and amphotericin B coadministration on the expression and specific hepatic distribution of F4/80: (A) control group; (B) $50 \mathrm{mg} / \mathrm{kg}$ flucytosine $+300 \mu \mathrm{g} / \mathrm{kg}$ amphotericin B group; (C) $100 \mathrm{mg} / \mathrm{kg}$ flucytosine $+600 \mu \mathrm{g} / \mathrm{kg}$ amphotericin B group; (D) $150 \mathrm{mg} / \mathrm{kg}$ flucytosine $+900 \mu \mathrm{g} / \mathrm{kg}$ amphotericin B group.

Detection of Kupffer cells by immunohistochemistry after antifungal treatment showed an increase in number of $\mathrm{F} 4 / 80^{+}$ cells in dose-dependent manner (Figure 5).

Electron microscopy investigations of experimental livers evidenced a normal ultrastructural aspect in the control group (Figure 6(A)). Antifungal coadministration causes dilatation of sinusoids and bile canaliculi, which join each other to form enlarged structures, devoid of microvilli, compared to control. These changes are dose-dependent. Kupffer cells became activated at highest dose of combined antifungal therapy, noticed by intense phagocytic activity (Figure $6 \mathrm{D}(1-$ 2)). Also, perisinusoidal fibrosis was present (Figure 6(D2)).

\section{Discussion}

Higher rates of mycoses are reported in hospitals, as a result of the increasing percent of immunocompromised patients at risk for invasive fungal infections, which in many cases are associated with high mortality rates and health care costs [15]. Furthermore, the common practice is to switch to a different class of antifungal agents or to combine therapies for the patients who fail the primary therapy or who experience intolerable adverse reactions [8].

Combined therapy of flucytosine and amphotericin B is the recommended first-line treatment for many invasive fungal infections, as disseminated cryptococcosis in both immunocompetent and immunosuppressed patients [7]. Because the side-effects of both monotherapies were established, in this study we aimed to evaluate the hepatotoxicity induced by combined therapy at increasing doses.
Acute hepatotoxicity induces inflammation and hepatocyte apoptosis or necrosis. In many cases, cell death is not owed to the damaging agent itself, but to the inflammation results. Histological analysis revealed an increase of parenchymal and portal inflammation in mice, in dosedependent manner. The inflammatory infiltrate seen in histological liver sections is a naturally occurring reaction of the system to damaged cells [16].

Hepatic inflammatory response is mediated by the proinflammatory cytokines, especially tumor necrosis factor- $\alpha$ (TNF- $\alpha$ ), which can further modulate the effects of other cytokines, as IL-1, IL-2, IL-4, IL-6, IL-10, IL-12, IL-18, and IL-23 [17]. Although almost detectable in the normal liver, production of TNF- $\alpha$ is one of the first events in many types of liver injury. As expected, in our mouse model, amphotericin B and flucytosine coadministration stimulated activation of an inflammatory pathway, demonstrated by a significant increase of TNF- $\alpha$ immunoreactivity. This was dosedependently increased by 50/300, 100/600, and 150/600 of flucytosine-amphotericin B cotreatment, suggesting that combined therapy exerts a synergistic inflammatory activation in a dose-dependent manner. Subsequently, activation of TNF receptors leads to induction of death signals, TNF- $\alpha$ being primarily involved in juxtacrine signaling of cytotoxicity. It has been shown recently that critical drug-induced toxicity pathways act in synergy with the proinflammatory TNF$\alpha$ [18]. TNF- $\alpha$ is a powerful promoter of the inflammatory response, directly or through stimulation of proinflammatory mediators, including IL- 6 secreted by Kupffer cells. IL- 6 is the predominant regulator of the hepatic acute-phase response 

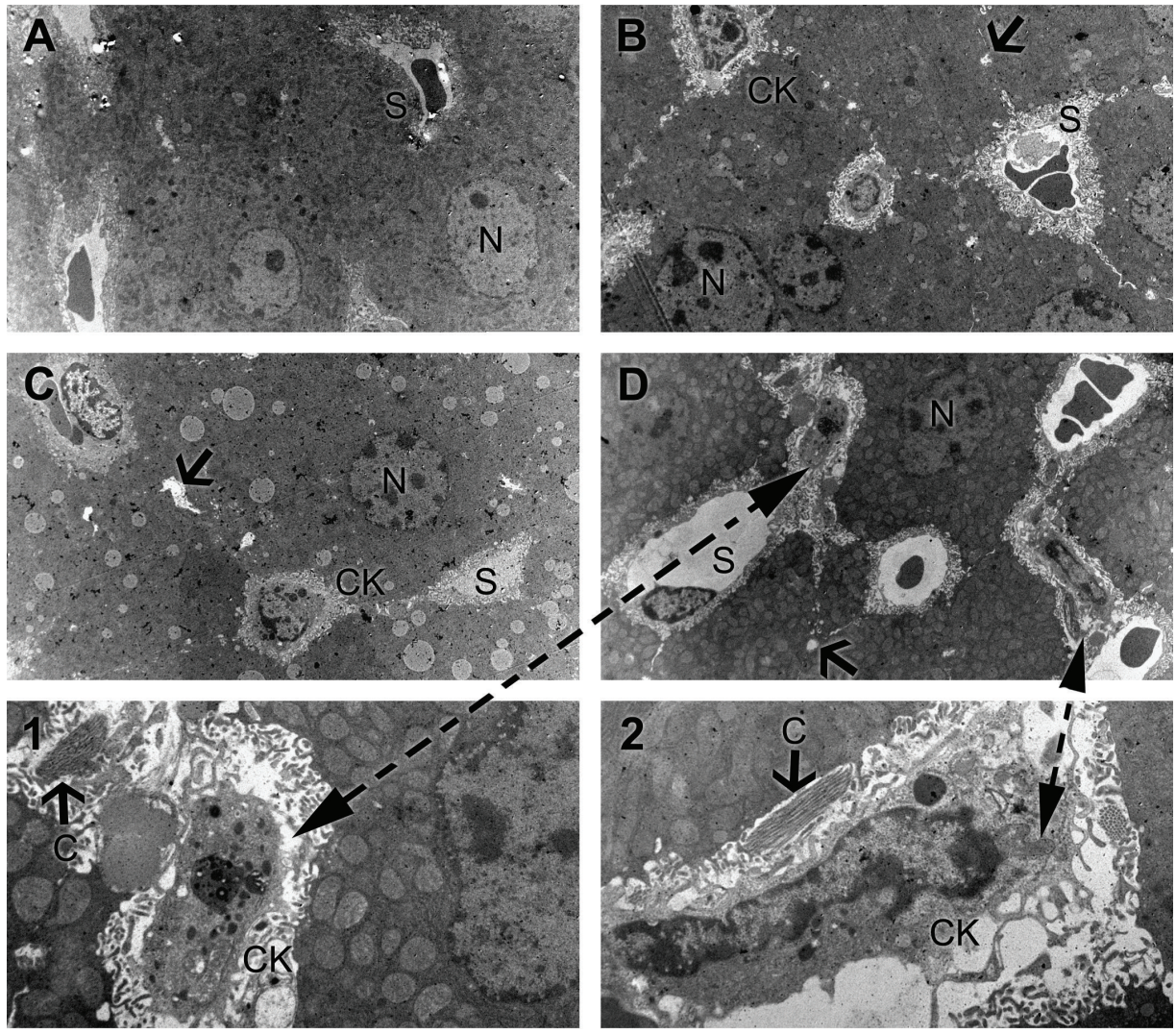

Figure 6: The effect of flucytosine and amphotericin B coadministration on ultrastructural changes in the livers of experimental mice: (A) control group; (B) $50 \mathrm{mg} / \mathrm{kg}$ flucytosine $+300 \mu \mathrm{g} / \mathrm{kg}$ amphotericin B group; (C) $100 \mathrm{mg} / \mathrm{kg}$ flucytosine $+600 \mu \mathrm{g} / \mathrm{kg}$ amphotericin B group; (D) $150 \mathrm{mg} / \mathrm{kg}$ flucytosine $+900 \mu \mathrm{g} / \mathrm{kg}$ amphotericin B group. $(1,2)$ Detail of activated Kuppfer cells and perisinusoidal fibrosis. N: nucleus, CK: Kuppfer cells, S: sinusoids, C: collagen, and arrow: dilated bile canaliculi.

and modulates liver fibrosis through degrading extracellular matrix proteins by inhibition of proteases or by binding to other cytokines $[19,20]$. Our study showed that IL-6 is stimulatory as suggested by higher levels in hepatic tissue and upregulation of target genes in mice with amphotericin B and flucytosine-induced liver inflammation. Similar trends were observed by Cho et al. [21] and Xiao et al. [22] for other xenobiotics.

$\mathrm{NF}-\kappa \mathrm{B}$ is a key transcription factor that plays a crucial role in the cellular response to signal transduction by TNF$\alpha$ and IL- 6 and is thereby involved in several signal transduction pathways of inflammatory response by controlling the expression of genes encoding cytokines [23]. NF- $\kappa \mathrm{B}$ is also known to activate the transcription of TNF- $\alpha$-inducible genes, including IL-1 [24]. Thus, TNF- $\alpha$ and IL- $1 \beta$ promote NF- $\kappa \mathrm{B}$ activation, both leading to enhanced production of supplementary proinflammatory cytokines. Following cellular stimulation, the I-kappaBs inhibitors, which in normal conditions sequester $\mathrm{p} 50 / \mathrm{p} 65$ dimers of NF- $\kappa \mathrm{B}$ in the cytoplasm, are rapidly degraded, activating NF- $\kappa \mathrm{B}$. The active form p 65 of NF- $\kappa \mathrm{B}$ rapidly translocates into the nucleus, binding to consensus sequences in the promoter/enhancer region of various genes, promoting their transcription, and regulating various inflammatory responses. Prolonged activation of $\mathrm{NF}-\kappa \mathrm{B}$ leads to perpetuated inflammatory response, which induced liver injury. This cycle can affect the structure and ultrastructure of the hepatocytes and impairs their function accordingly. In our study, NF- $\kappa$ B p 65 was activated after antifungal treatment, demonstrated by dose-dependent increased immunohistochemical expression and upregulation of target genes (Figure 4).

Kupffer cells are resident macrophages of the liver and play an important role in the pathogenesis of liver injury mediated by chemical substances, toxins, and pharmacological agents. Activation of Kupffer cells by toxic agents results in the release of inflammatory mediators, growth factors, and reactive oxygen species and further modulates acute hepatocyte injury [25].

In response to proinflammatory signals of antifungal administration, Kupffer cells become activated, revealed by increased number of $\mathrm{F} 4 / 80^{+}$cells (Figure 5).

In addition, ultrastructural analysis strengthens immunohistochemical observations, showing that the Kupffer cells from antifungal treated livers were enlarged with increased secretory vesicles and phagocytic activity (Figure 6). Direct or indirect activation of Kupffer cells by toxic agents results in the release of an array of inflammatory mediators including cytokines, growth factors, and reactive oxygen species [26]. This activation appears to modulate acute hepatocyte injury [25], noticed by us through increased 
production of TNF- $\alpha$ and IL-6 under combined flucytosineamphotericin B treatment, in a dose-dependent manner (Figures 2 and 3).

\section{Conclusions}

Our results suggest that antifungal combined therapy exerts a synergistic inflammatory activation in a dose-dependent manner, through NF- $\kappa$ B pathway, which promotes an inflammatory cascade during inflammation.

The use of amphotericin B and flucytosine in combined therapy needs to be dose limiting due to the associated risk of liver injury, especially for those patients with hepatic dysfunction, requiring careful monitoring along antifungal therapy.

\section{Conflict of Interests}

The authors declare that there is no conflict of interests regarding the publication of this paper.

\section{Authors' Contribution}

Alexandra Folk and Coralia Cotoraci contributed equally to this work.

\section{Acknowledgments}

A. Folk acknowledges the Strategic Grant POSDRU/159/1.5/ S/133391 within the project "Doctoral and Post-Doctoral Programs of Excellence for Highly Qualified Human Resources Training for Research in the Field of Life Sciences, Environment and Earth Science" cofinanced by the European Social Fund within the Sectorial Operational Program Human Resources Development 2007-2013. This research was also financed by the Institute for Research of the University of Bucharest (ICUB), through "Scholarships for Excellence in Research for Young Researchers, 2015 Competition” Project and START Project: BEST-NetWORK 16_PA07-C1.

\section{References}

[1] P. G. Pappas, C. A. Kauffman, D. Andes et al., "Clinical practice guidelines for the management of candidiasis: 2009 Update by the Infectious Diseases Society of America," Clinical Infectious Diseases, vol. 48, no. 5, pp. 503-535, 2009.

[2] M. Klepser, "The value of amphotericin B in the treatment of invasive fungal infections," Journal of Critical Care, vol. 26, no. 2, pp. 225.el-225.e10, 2011.

[3] K. C. Gray, D. S. Palacios, I. Dailey et al., "Amphotericin primarily kills yeast by simply binding ergosterol," Proceedings of the National Academy of Sciences of the United States of America, vol. 109, no. 7, pp. 2234-2239, 2012.

[4] E. Wilson, L. Thorson, and D. P. Speert, "Enhancement of macrophage superoxide anion production by amphotericin B," Antimicrobial Agents and Chemotherapy, vol. 35, no. 5, pp. 796800, 1991.

[5] A. Vermes, H.-J. Guchelaar, and J. Dankert, "Flucytosine: a review of its pharmacology, clinical indications, pharmacokinetics, toxicity and drug interactions," Journal of Antimicrobial Chemotherapy, vol. 46, no. 2, pp. 171-179, 2000.
[6] J. E. Bennett, W. E. Dismukes, R. J. Duma et al., "A comparison of amphotericin B alone and combined with flucytosine in the treatment of cryptococcal meningitis," The New England Journal of Medicine, vol. 301, no. 3, pp. 126-131, 1979.

[7] M. S. Saag, R. J. Graybill, R. A. Larsen et al., "Practice guidelines for the management of cryptococcal disease," Clinical Infectious Diseases, vol. 30, no. 4, pp. 710-718, 2000.

[8] D. A. Enoch, H. A. Ludlam, and N. M. Brown, "Invasive fungal infections: a review of epidemiology and management options," Journal of Medical Microbiology, vol. 55, no. 7, pp. 809-818, 2006.

[9] J. L. Wang, C. H. Chang, Y. Y. Xu, and K. A. Chan, "Systematic review and meta-analysis of the tolerability and hepatotoxicity of antifungals in empirical and definitive therapy for invasive fungal infection," Antimicrobial Agents and Chemotherapy, vol. 54, no. 6, pp. 2409-2419, 2010.

[10] N. Somchit, J. H. Chung, A. Yaacob, Z. Ahmad, Z. A. Zakaria, and A. A. Kadir, "Lack of hepato- and nephrotoxicity induced by antifungal drug voriconazole in laboratory rats," Drug and Chemical Toxicology, vol. 35, no. 3, pp. 304-309, 2012.

[11] M. Soltani, C. M. Tobin, K. E. Bowker, J. Sunderland, A. P. MacGowan, and A. M. Lovering, "Evidence of excessive concentrations of 5 -flucytosine in children aged below 12 years: a 12-year review of serum concentrations from a UK clinical assay reference laboratory," International Journal of Antimicrobial Agents, vol. 28, no. 6, pp. 574-577, 2006.

[12] P. Schwarz, F. Dromer, O. Lortholary, and E. Dannaoui, "Efficacy of amphotericin B in combination with flucytosine against flucytosine-susceptible or flucytosine-resistant isolates of Cryptococcus neoformans during disseminated murine cryptococcosis," Antimicrobial Agents and Chemotherapy, vol. 50, no. 1, pp. 113-120, 2006.

[13] K. J. Livak and T. D. Schmittgen, "Analysis of relative gene expression data using real-time quantitative PCR and the 2$\Delta \Delta \mathrm{C}(\mathrm{T})$ method," Methods, vol. 25, no. 4, pp. 402-408, 2001.

[14] J. M. Austyn and S. Gordon, "F4/80, a monoclonal antibody directed specifically against the mouse macrophage," European Journal of Immunology, vol. 11, no. 10, pp. 805-815, 1981.

[15] M. J. G. T. Rüping, J. J. Vehreschild, and O. A. Cornely, "Patients at high risk of invasive fungal infections: when and how to treat," Drugs, vol. 68, no. 14, pp. 1941-1962, 2008.

[16] M. M. Markiewski, R. A. DeAngelis, and J. D. Lambris, "Liver inflammation and regeneration: two distinct biological phenomena or parallel pathophysiologic processes?" Molecular Immunology, vol. 43, no. 1-2, pp. 45-56, 2006.

[17] M. J. Weiss, "Cytokines in liver, biliary, and pancreatic disease," in Blumgart's Surgery of the Liver, Pancreas and Biliary Tract, chapter 10, pp. 166-180, Saunders, 2012.

[18] L. Fredriksson, S. Wink, B. Herpers et al., "Drug-induced endoplasmic reticulum and oxidative stress responses independently sensitize toward TNF $\alpha$-mediated hepatotoxicity," Toxicological Sciences, vol. 140, no. 1, pp. 144-159, 2014.

[19] I. Choi, H.-S. Kang, Y. Yang, and K.-H. Pyun, "IL-6 induces hepatic inflammation and collagen synthesis in vivo," Clinical and Experimental Immunology, vol. 95, no. 3, pp. 530-535, 1994.

[20] C. A. Norris, M. He, L.-I. Kang et al., "Synthesis of IL-6 by hepatocytes is a normal response to common hepatic stimuli," PLoS ONE, vol. 9, no. 4, Article ID e96053, 2014.

[21] B.-O. Cho, H.-W. Ryu, Y. So et al., "Hepatoprotective effect of 2,3-dehydrosilybin on carbon tetrachloride-induced liver injury in rats," Food Chemistry, vol. 138, no. 1, pp. 107-115, 2013. 
[22] J. Xiao, E. C. Liong, Y. P. Ching et al., "Lycium barbarum polysaccharides protect rat liver from non-alcoholic steatohepatitisinduced injury," Nutrition and Diabetes, vol. 3, article e81, 2013.

[23] J. Pękalski, P. J. Zuk, M. Kochańczyk et al., "Spontaneous NF$\kappa \mathrm{B}$ activation by autocrine $\mathrm{TNF} \alpha$ signaling: a computational analysis," PLoS ONE, vol. 8, no. 11, Article ID e78887, 2013.

[24] T. Lawrence, "The nuclear factor NF- $\kappa$ B pathway in inflammation," Cold Spring Harbor Perspectives in Biology, vol. 1, Article ID a001651, 2009.

[25] R. A. Roberts, P. E. Ganey, C. Ju, L. M. Kamendulis, I. Rusyn, and J. E. Klaunig, "Role of the Kupffer cell in mediating hepatic toxicity and carcinogenesis," Toxicological Sciences, vol. 96, no. 1, pp. 2-15, 2007.

[26] G. Kolios, V. Valatas, and E. Kouroumalis, "Role of Kupffer cells in the pathogenesis of liver disease," World Journal of Gastroenterology, vol. 12, no. 46, pp. 7413-7420, 2006. 

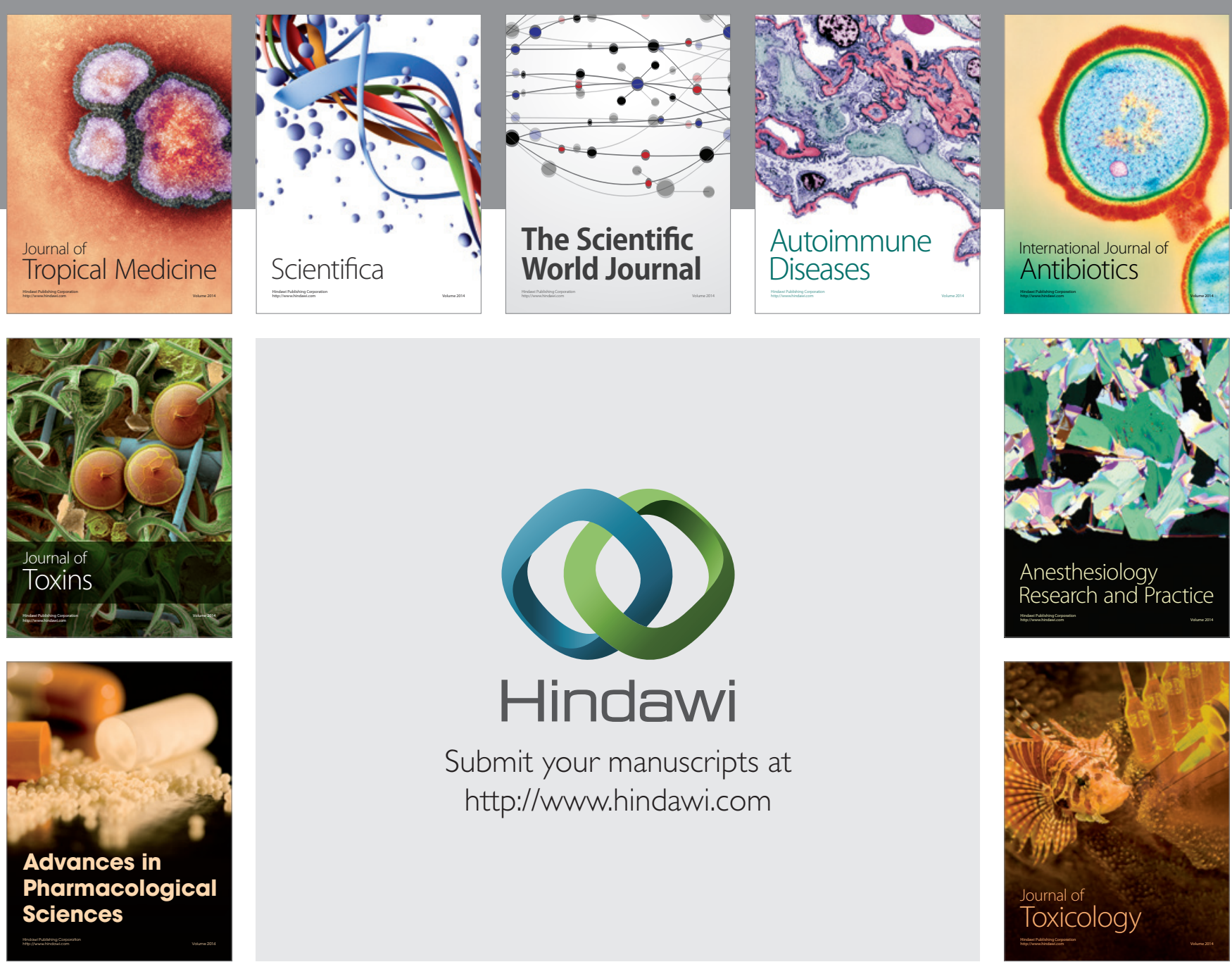

\section{Hindawi}

Submit your manuscripts at

http://www.hindawi.com
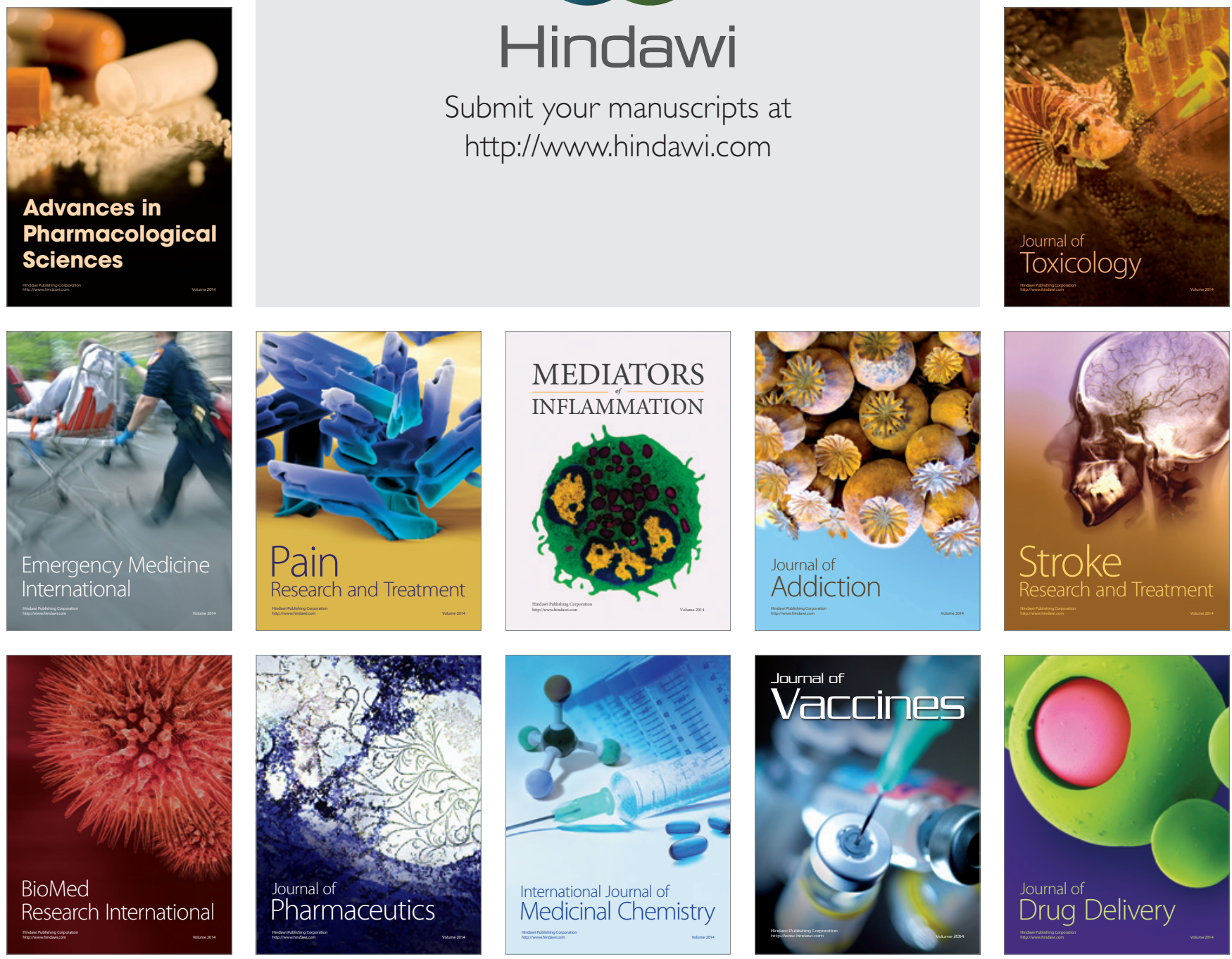